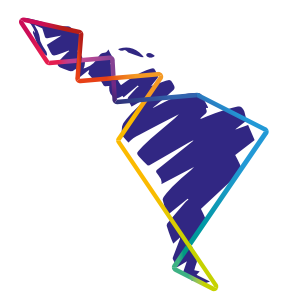

\title{
Indeterminación territorial y derecho a la ciudad para habitantes indígenas de la comuna de San José de Cocotog
}

\author{
Territorial indetermination and \\ right to the city for indigenous \\ inhabitants of the commune of San \\ José de Cocotog
}

\author{
Indeterminação territorial e direito à \\ cidade dos habitantes indígenas da \\ comuna de San José de Cocotog
}

Aníbal Josueth Aguilar Poveda'

\begin{abstract}
Resumen
La presente investigación focaliza al derecho a la ciudad como uno humano básico al que deberían acceder todos los habitantes de la comuna indígena de San José de Cocotog, ubicados en el Distrito Metropolitano de Quito, Ecuador. Este espacio se encuentra dividido, espacial como simbólicamente, por las administraciones zonales Calderón y Eugenio Espejo, así como las juntas parroquiales de Zámbiza y Llano Chico. Con esta base, se interpreta la influencia que ha generado la indeterminación territorial en el acceso, ejercicio y disfrute de los derechos humanos. El estudio recurre a la metodología cualitativa, como aquella perspectiva que facilita el diálogo con los participantes y, sea su expresión la que problematiza y amplía el debate de la situación de su comuna en torno al actual Estado de Derechos. En este marco, se realizan entrevistas a los dirigentes sociales y parroquiales, además, se efectúa un grupo de discusión con habitantes de cada uno de los cinco barrios de la Cocotog. Los resultados prestan importancia fundamental
\end{abstract}

Recibido: 4-12-2020 - Aceptado: 13-5-2021

1 Nacionalidad ecuatoriana, actualmente vive en la ciudad de Quito. Investigador en el Municipio de Quito (Observatorio Metropolitano de Seguridad Ciudadana). Psicólogo social y comunitario (Universidad Politécnica Salesiana) y especialista superior en Derechos Humanos (Universidad Andina Simón Bolívar/ Afiliación). Estudios actuales en Maestría en Investigación en Derecho Humanos con mención en América Latina. Correo electrónico: jiro_lqqd@yahoo.com. (D) https://orcid.org/0000-0001-7439-9227 
al territorio, debido a que es en este lugar donde los sujetos se relacionan y desarrollan, tanto personal como colectivamente, no obstante, se encuentran atravesados por vulneraciones y desigualdades por efecto de la división espacial. La ausencia de reconocimiento de sus límites ha generado segregación social, limitantes y carencias de espacios públicos, deslegitimación de la organización comunal, así como una amplia sensación de desamparo institucional en lo que respecta al acceso de obras públicas que favorezcan la vida digna de sus habitantes.

Palabras clave: derechos humanos, territorio, dignidad, comuna.

\begin{abstract}
The present research focuses on the right to the city as a basic human right that should be accessed by all the inhabitants of the indigenous community of San José de Cocotog, located in the Metropolitan District of Quito, Ecuador. The commune is divided, territorially and symbolically, by the regional administrations Calderón and Eugenio Espejo, as well as the parish councils of Zámbiza and Llano Chico. On this basis, the influence generated by territorial indeterminacy in access to the right to the city is interpreted.
\end{abstract}

The study uses qualitative methodology, as that perspective that facilitates dialogue with the participants and, allow their expression to problematize and broaden the debate on the situation of their commune regarding this right and the current State of Rights. In this framework, interviews are conducted with community and parish leaders, in addition, a discussion group is held with inhabitants of each of the five neighborhoods of the commune.

The results ascribe fundamental importance to the territory, as it is in this place where the subjects relate and develop, both personally and collectively, however, they are traversed by violations and inequalities due to the effect of territorial division. The absence of recognition of territorial limits has generated social segregation, limitations and lack of public spaces, delegitimization of the communal organization, as well as a wide sensation of institutional helplessness with regard to access to public works that favor a dignified life of its inhabitants.

Keywords: Human rights; Territory; Dignity; Commune.

\title{
Resumo
}

Esta pesquisa enfoca o direito à cidade como um direito humano básico que deve ser acessado por todos os habitantes da comunidade indígena de San José de Cocotog, localizada no Distrito Metropolitano de Quito, Equador. A comuna está dividida, territorial e simbolicamente, pelas administrações regionais Calderón e Eugenio Espejo, bem como pelas juntas de freguesia de Zámbiza e Llano Chico. Com base nisso, interpreta-se a influência gerada pela indeterminação territorial no acesso ao direito à cidade.

O estudo utiliza metodologia qualitativa, como aquela perspectiva que facilita o diálogo com os participantes e, é sua expressão que problematiza e amplia o debate sobre a situação de seu 
município a respeito desse direito e do atual Estado de Direitos. Neste quadro, são realizadas entrevistas com os líderes comunitários e paroquiais, além disso, é realizado um grupo de discussão com os habitantes de cada um dos cinco bairros da comuna.

Os resultados conferem fundamental importância ao território, pois é neste local onde os sujeitos se relacionam e se desenvolvem, tanto pessoal quanto coletivamente, porém, são atravessados por violações e desigualdades devido ao efeito da divisão territorial. A ausência de reconhecimento de limites territoriais gerou segregação social, limitações e carência de espaços públicos, deslegitimação da organização comunal, bem como uma ampla sensação de desamparo institucional no que se refere ao acesso a obras públicas que favoreçam uma vida digna de seus habitantes.

Palavras-chave: Direitos humanos; Território; Dignidade; Comuna

\section{Introducción}

El territorio de San José de Cocotog, atraviesa una disyuntiva en torno a su administración. Son en algunos casos, atendidos por la junta parroquial de Llano Chico y, otras ocasiones, Zámbiza. Así mismo, las administraciones zonales de Calderón y Eugenio Espejo prestan una atención intermitente a sus habitantes. La segmentación de Cocotog en dos partes, ha ocasionado que la búsqueda de cambios que mejoren las condiciones de sus habitantes, se vea interrumpida, detenida o no se han efectuado por motivos de competencias administrativas.

Los conflictos territoriales, la fragmentación espacial y la desigualdad en el acceso a la ciudad, son algunos factores que se abordan con la intención de argumentar las causas, por las que, las competencias de dos administraciones territoriales en la comuna de Cocotog, han decantado en inconformidad generalizada de los habitantes en la aceptación de su respuesta. En otras palabras, no han generado condiciones socio materiales que permitan habitar el espacio rural, es decir, bajo condiciones justas en la manera de vivir.

La ausencia de reconocimiento territorial, la cual se entiende como el conflicto en los límites espaciales e injerencia administrativa diferenciada, ha generado segregación social, exclusión y discriminación, entre otras vulneraciones. Todo esto en vista de la falta de operatividad de la acción estatal para responder a sus habitantes como una totalidad, es decir, como comuna indígena de San José de Cocotog y no como barrios adscritos a cierta institución con competencia específica.

Lo planteado se refleja en aspectos como la carencia de obras públicas, acceso deteriorado de las vías, sin monumentalidad identitaria, casi nulos espacios de recreación para la diversidad de habitantes. Bajo este contexto, se entiende a la ciudad como "vida urbana renovada [...], donde hay un goce pleno y efectivo de 
los derechos humanos $[y]$ el contexto urbano no es el lugar de las penurias, sino el lugar de la vida digna" (Montoya, 2010, p. 135). Habría que decir, por tanto, que esta perspectiva ve a al territorio "más que una institución, [pues] puede ser un elemento de vital importancia para la garantía de los derechos humanos de sus habitantes o, por el contrario, un nefasto ejemplo de vulneración" (Montoya, 2010, p. 135).

La investigación lleva a preguntarse respecto a la manera en que influye la indeterminación territorial de la comuna indígena de San José de Cocotog en el acceso al derecho a la ciudad en sus habitantes. Para el cometido se plantean varios objetivos que coadyuvan a dilucidar esta interrogante, por tanto, amerita discutir cómo la dimensión espacial transversaliza la interpretación en poblaciones rurales y diversas, posteriormente, identificar e indagar cómo los participantes dan cuenta de la situación y limitaciones producto de la segmentación.

Se opta por abordarla desde el enfoque cualitativo, el cual se interesa por los sentidos y las interpretaciones que los habitantes aluden en torno a la situación de su comuna, atravesada por el problema de determinación limítrofe. Se resalta la implementación de las técnicas como la entrevista y grupo de discusión, útiles para conocer e profundizar los sentidos que se hacen de la realidad que atraviesan.

Las herramientas mencionadas aportaron en la obtención de significaciones que los dirigentes locales y las autoridades parroquiales tienen de la singularidad del espacio comunal, las relaciones con este, la manera en que conciben la indeterminación territorial y, finalmente, sus efectos y requerimientos como mecanismo de solución a la situación limítrofe.

La totalidad de las personas que aportaron con información para las entrevistas y el grupo de discusión fueron seleccionadas con base en el muestreo no probalístico conocido como intencional opinático. Este prioriza el conocimiento de los participantes, en torno a la calidad de la información respecto a la situación de la comuna, sus barrios y la temática limítrofe.

El análisis de las fuentes recolectadas se ejecutó mediante categorización. Los datos descriptivos de los diálogos mantenidos, generó información primaria sobre el espacio y las relaciones que se producen en este, para, finalmente, contrastar los resultados obtenidos en torno al acceso al derecho a la ciudad. Este abordaje permitió conocer los factores que están limitando y mermando el efectivo goce de este derecho en los habitantes de la comuna.

\section{Marco teórico}


Se concibe a la ciudad y a sus habitantes desde una constante búsqueda que viabilice las trasformaciones urbanas, coadyuven a la cohesión social, la integralidad personal como colectiva, así como la identidad cultural (Roa López, 2012). La ciudad, por tanto, debe ser pensada como alude Margarita Jans, es decir, en términos de espacialidad, funcionalidad, simbolismo o significados construidos (Jans, 2005).

No solo se trata del acceso y del uso de la ciudad y sus espacios, sino también, la posibilidad de resignificarlos y transformarlos. Supone la construcción de un ambiente de bienestar para todos los habitantes, diverso y accesible, en general, donde los sujetos habiten sus territorios como un lugar "de contacto e identificación entre las personas, de animación urbana y de expresión comunitaria" (Laguna, 2013, p. 54). Así mismo, existan escenarios que posean elementos culturales que les permitan "la cohesión social y la identidad cultural" (Roa López, 2012, p. 107).

\section{El derecho a la ciudad y su interdependencia}

En lo que se refiere a las condiciones jurídicas de este derecho, para su disfrute y exigibilidad, es necesario recalcar que su discusión está relacionada con otras condiciones humanas esenciales. Por ejemplo, seguridad, territorio, movilidad, ambiente, entre otros, por tanto, la ciudad está atravesado por el reconocimiento interdependiente de condiciones que generen una vida digna y de calidad para sus habitantes.

La ciudad no es un elemento constituido e inmóvil, en su lugar, hay que entenderla desde "las huellas que su historia ha dejado en ella [...] observarla e intervenirla en su presente y realidad, pensarla en las proximidades e imaginarla y soñarla siglos adelante" (Montoya, 2010, p. 147). Lo expuesto plantea, de manera latente, la responsabilidad estatal para ir incorporando cambios que favorezcan la realización de los derechos y, las acciones y las omisiones, se verán plasmadas en los territorios, afectando a gran cantidad de habitantes, no únicamente a sujetos individuales.

El derecho a la ciudad se concibe como histórico y variante, los cuales devienen y se transforman acorde a cambios, necesidades y reivindicaciones, producto de la evolución de las sociedades. Si se sostiene que los sujetos interpretan su realidad y son agentes de transformación de sus condiciones de vida, esto se debe a que "no son construidas al momento, [...] vienen moduladas por la cultura y la estructura social dentro de la cual la persona opera" (Valera, 1999, 13). En definitiva, se resalta la progresividad en la protección y pleno disfrute, es decir, "la codificación y positivización de este derecho es un proceso dinámico que depende de la evolución de las sociedades" (Roa, 2012, p. 127). 


\section{Derecho al espacio público}

Entre la diversidad de conceptos que integran la concepción de ciudad, se halla el espacio público, entendido como la morfología física que facilita el acceso y tránsito, es decir, la accesibilidad (Roa, 2012). Definitivamente, es en estos lugares donde se percibe el tratamiento que los distintos niveles del Estado operativizan sus recursos, es decir, la forma como se invierte de manera equitativa para todos los territorios (Salazar et ál., 2017). La falta de respuesta Estatal para garantizar lugares de calidad, pone en riesgo a sus habitantes, pues, como menciona Jordi Borja, sin estos sitios, la ciudad se disuelve (Borja, 2011).

La focalización sobre el espacio público, como elemento primordial en el derecho a la ciudad, muestra cómo en la realidad es en este lugar donde se busca "la libertad, la igualdad, la tolerancia, el respeto a la naturaleza, la seguridad, la democracia, el buen gobierno y la justicia, [...] pues todos estos valores se materializan en este escenario" (Roa, 2012, p. 105).

En este punto, es importante considerar al lugar-territorio como un elemento articulador en el que puedan desarrollarse personal como colectivamente, no como se viene dando de manera polarizada, es decir, como un medio de producción. Se insta, por tanto, a entenderlo por los sentidos y vivencias que genera, además de ser el espacio en que se objetiviza las condiciones socio materiales para su existencia (Gonçalves, 2016).

\section{Diversidad y territorio}

La ciudad "se descubre como un espacio de política, ya que es donde se produce el encuentro de lo que es diverso, [...] a la misma vez el conflicto, contacto [y] asociación que promueve el desarrollo de complejos procesos sociales" (Alguacil, 2008. p. 51). Como lo hace notar Lucas Correa Montoya, también se la entiende como un collage donde la diversidad de habitantes, su diferencia, son aspectos que deben ser incorporados en prácticas democráticas y, sea su incidencia transformadora, la acción política que dote de sentido y favorezca el ejercicio de los derechos humanos en el territorio (Correa Montoya, 2012).

Es en la ciudad donde se ponen en evidencia las desigualdades existentes, en particular, cuando desde la respuesta Estatal se da un trato desfavorecido a las comunidades rurales e indígenas. Lo mencionado resalta lo que Pradilla sostiene como desarrollo desigual, pero no solo en comparación entre países, sino dentro de los mismos espacios territoriales de un estado (Cobos, 2014). 
No hay que olvidar que la tierra en poblaciones indígenas, atravesaron varios conflictos en el periodo de la conquista y la colonia. Su territorios fueron usufructuados sistemáticamente "sentando las bases de la [...] legitimación de las formas de despojo de sus territorios que permanecerán hasta el presente" (Castro, 2010b, p. 198).

El territorio además de poner de manifiesto las desigualdades, también coloca en movimiento las decisiones colectivas para la resolución de sus condiciones, por lo tanto, la ciudad es un espacio en disputa, (Durán et ál., 2016). A la vez, es un lugar de negociación y concertación en la que se incide mediante la participación en la producción y la transformación de su entono.

Es necesario recalcar que no se propone, solamente, una ciudad en la que se vele por el acceso a esta, sino también, que todos los sujetos gocen de las mismas condiciones, oportunidades de transformarla y mecanismos para el efectivo ejercicio de sus derechos. Caso contrario, evidencia cuando se gestan propuestas e iniciativas desde el Estado, pero, estas no toman en cuenta la identidad de los habitantes, los símbolos locales compartidos, su historia y su relación con el territorio, (Madanipour, et ál., 122) lo cual, decanta en respuestas sin profundidad y verdadero cambio para sus habitantes.

\section{Segregación urbana}

En la ciudad y, principalmente en el espacio rural, el derecho a la urbe debe ser abordado desde una óptica diferente, sin discriminar y ampliar las brechas, sino como un intento de "recuperar la heterogeneidad como principio individualizante de construcción de la ciudadanía [...], sin que ello excluya la necesidad de conceptualizar la heterogeneidad social en términos de desigualdad" (Misses-Liwerant, 2016, p. 11).

Es esencial comprender que la noción de ciudad encubre entre sus concepciones la distinción entre lo rural y lo urbano, incorporando a esta última la mayor cantidad de oportunidades, lo cual reproduce una clara distinción de relaciones en la manera en que se accede a la vida en la urbe, por tanto, el orden espacial diferenciado esconde en sí mismo condiciones de segregación, desequilibrio y fragmentación.

Muestra de lo expuesto se halla el empeoramiento del hábitat de las comunas rurales en la Ciudad de Quito, dado que estas concentran botaderos de basura y escombreras en sus territorios, además, tienen serios problemas para el uso saludable del agua para sus cosechas, en vista de la contaminación que sucede cuando este recurso atraviesa las urbes e ingresan a Cocotog. 
Por otro lado, las nuevas catalogaciones en las rentas de suelo se han convertido en un patrón de expulsión de los habitantes, es decir, el cambio de régimen de rural a urbano ha implicado la dificultad para conservar sus tierras, en razón del incremento de costo de predios, por tanto, hace impensable afrontar esta realidad cuando en poblaciones indígenas en el nivel rural, como es el caso de Cocotog, los ingresos económicos no son altos, pues se obtienen de la cosecha de ciclos cortos y la crianza de ganado.

\section{Normativa en derecho a la ciudad}

La normativa nacional que vela por el derecho a la ciudad y, también cobija a las poblaciones indígenas, se verá plasmada en la Carta Magna del Ecuador del año 2008. Este instrumento nacional (Art. 31) postula la positivización normativa que tienen todas las personas para el disfrute de la ciudad y sus espacios públicos, resaltando el equilibrio que se debe prestar entre lo urbano y lo rural y el respeto por las distintas culturas, además, destaca el ejercicio ciudadano, como la participación, para viabilizar sus requerimientos y la protección de sus entornos. (Constitución de La República Del Ecuador, 2008).

La definición del estándar más alto se constata en Carta de la Ciudad de México, pues coloca a los habitantes en la promoción de los ya existentes y en la búsqueda de reconocimiento de nuevos (emergentes). En términos de esta normativa, se sostiene que "no se limita a reivindicar los derechos humanos en un territorio, sino que implica obligaciones de la autoridad y responsabilidades de la población en la gestión, producción y desarrollo de la ciudad" (Carta de la Ciudad de México por el Derecho a la Ciudad, 2010).

Este tipo de corresponsabilidad implica "que la propiedad del Estado no solamente esté bajo el control de los administradores del Estado sino, gradualmente, bajo el control de la propia sociedad" (Schiavo et ál., 2017, p. 309). Aun en este criterio, es importante resaltar la obligación Estatal, para garantizar una ciudad que dignifique, tanto a la comuna, como a sus habitantes y, estos vean en sus territorios, la realización de sus derechos. Dicho de otra manera, quienes viven en Cocotog tampoco deben suplir toda la responsabilidad que la institucionalidad no lleva a cabo.

\section{Metodología}

Se subraya la importancia que tiene el método fenomenológico, como la característica que orienta el enfoque cualitativo y uso de herramientas en la investigación. Este procedimiento tiene la cualidad de posibilitar un mejor acercamiento hacia las descripciones y los significados que los habitantes enfatizan respecto a la situación 
de la comuna y de su experiencia atravesada por la temática limítrofe. Es importante resaltar que esta perspectiva no reduce al sujeto a una mirada introspectiva de contenidos interiores, puesto que, también permite la comprensión de la relación de estos con sus vivencias en el devenir social e histórico (Guedes \& Moreira, 2009).

En orden secuencial del levantamiento, los instrumentos se implementaron de la siguiente manera: en primer lugar, se realizó entrevistas semiestructuradas, tanto a dirigentes de cada uno de los cinco barrios de la comuna, ${ }^{2}$ así como, al presidente del Cabildo. Además, se dialogó con los principales representantes de las juntas parroquiales de Llano Chico y Zámbiza.

Para el grupo de discusión se optó por dialogar con habitantes de cada uno de los cinco barrios de la comuna. Esta estrategia fue necesaria para recoger las experiencias de los entrevistados, respecto a la singularidad de su espacio territorial rural en la comuna indígena de San José de Cocotog.

El muestreo se orientó a la selección de aquellas personas que garanticen mejor: a) La cantidad (saturación) y, b) la calidad (riqueza) de la información. Respecto al primer punto, el levantamiento se vio concluido cuando la información ya no profundizaba o mostraba otras características del tema de interés del estudio, debido también, a la renuencia de los participantes a mencionar y dialogar por la misma línea argumental.

Finalmente, tanto la búsqueda de información, sistematización y análisis se efectúa en el año 2019. Para el análisis de las fuentes recolectadas, producto del uso de los instrumentos de levantamiento, se ejecutó la estrategia de categorización. Específicamente, se trata de "una operación de clasificación de elementos constitutivos de un conjunto por diferenciación, tras la agrupación por analogía, a partir de criterios previamente definidos" (Andreú, 2002, p. 15).

\section{Resultados}

A continuación, se analiza las principales características en torno a las afectaciones que ha tenido la problemática identificada como indeterminación territorial en los habitantes de la Comuna de Cocotog. Primeramente, en su conformación en el año 1943, y ratificada desde 1948, aparece adscrita a la Parroquia de Zámbiza, con los límites que hasta en la actualidad son percibidos por sus habitantes.

2 Los barrios que conforman la Comuna de San José de Cocotog son los siguientes: Central, Santa Ana, San Miguel, Jesús del Gran Poder y Yurac Alpaloma. 
Posteriormente, los habitantes deben aceptar su nueva adjudicación a Llano Chico en el año 1993, tiempo en que se ejecuta el Registro Oficial n. ${ }^{\circ} 342$, (Mérida, 2016) y gran porcentaje de los habitantes de la Comuna pasan a formar parte de esta parroquia, sin previo acercamiento, socialización o consulta.

La problemática sugiere una búsqueda de intereses o mal agenciamiento municipal y estatal en la división territorial, es decir, no tomó en cuenta lo que sucede al interior de Cocotog, su pertenencia e historia, libre determinación y arraigo territorial, provocando desmembramiento, desunión, limitantes en el acceso de obras y un vaivén institucional en el agenciamiento y el reclamo de sus derechos.

"La división de la Comuna" es la característica distintiva que los participantes asumen como indeterminación territorial. La idea de que en Cocotog solo existes barrios y calles refleja la descripción resumida, es decir, las autoridades desconocen la realidad de este sector, desarticulándola en barrios (Mérida, 2016).

En estos términos, la acción de dividir, está adjudicada a las instituciones del gobierno parroquial, los cuales esconden su interés de desarticular a la comunidad para facilitar el control de sus espacios territoriales. La división administrativa de la comuna puede estar relacionada con mejorar su respuesta en el nivel local, pero con el coste de desarticularla.

Los intereses de la ampliación territorial por parte de los GAD (Gobiernos Autónomos Descentralizados), en especial Llano Chico, se refleja en el requerimiento de inscripción en su parroquia, lo cual repercutiría en una mayor asunción presupuestaria por efecto del incremento de habitantes en su territorio.

Bajo este criterio, Jordi Borja hace notar las afectaciones que este interés presupuestario y territorial tendrían para los habitantes, por ejemplo, el derecho al desarrollo, la identidad del territorio y, a permanecer en un lugar elegido libremente y sin presiones estatales (Borja, 2015). En suma, se argumenta que los habitantes deben elegir a sus gobernantes, de tal manera, adquieran “...legitimidad democrática. Y para garantizar que se tiene en cuenta más a las personas que a los kilómetros cuadrados" (Borja, 2015, p. 29).

Los diálogos mantenidos en el grupo de discusión, revelan que la mayor cantidad de entrevistados aluden a que la respuesta ideal a la indeterminación territorial sería formar parte del GAD de Zámbiza, debido a un sentimiento de pertenencia ancestral de sus antepasados. Lo planteado hace explicito como el Estado no ha protegido los derechos identitarios, pues la división de la comuna en dos sectores territoriales no valorizó los vínculos con base en su asidero territorial. Lo expuesto 
se problematiza en palabras de Carlos López Roa cuando asevera que los cambios vivenciados en el nivel de ciudad no deben afectar la cohesión y afinidad local (Roa, 2012).

Cuando se destaca que los GAD velan por sus barrios específicos, esto también repercute en la manera en que los presupuestos participativos no son dados desde una mirada integral como comuna, esto es, valorando sus necesidades y vulnerabilidades. Por ejemplo, Cocotog en su globalidad tiene problemáticas que se deben responder como tal, pero al darse una respuesta focalizada en segmentos, se coarta una acción efectiva y se la deja fragmentada en sus mejoras y cambios.

Simultáneamente, el hecho de viabilizar el acceso a bienes y servicios de una manera diferenciadora y desigual, es decir, dependiendo el barrio, revela como la respuesta Estatal tiende a una injerencia inequitativa, distintiva y fragmentaria. Lo expuesto revela que no se garantiza el disfrute de los derechos humanos en los habitantes de la Comuna de San José de Cocotog en igualdad de condiciones.

Se resalta que el derecho a la ciudad es entendido como redistribución urbana ordenada y equilibrada que, para el caso de Cocotog, al no ser agenciado efectivamente por el Estado, ha decantado en un proceso sistemático de desconfianza institucional y, colateralmente, ha repercutido en un sentimiento de desamparo y exclusión.

La discriminación que se produce se da, más que a una persona o grupos específicos, a barrios en detrimento de aquellos que no forman parte de sus añejos, a su vez, a la comuna al no tratar sus problemáticas como una totalidad, sino como segmentos erróneamente diferenciados. Baste como ejemplo, el acceso a obras, las cuales no pueden ser gestionadas como una totalidad, pues únicamente se las tramita o agencia en nombre de un sector.

A continuación, se describe el estado de los espacios públicos de la comuna y la manera en que la problemática limítrofe ha influido en su valoración y garantía de acceso para todos sus habitantes; la mayoría de participantes no identifican lugares de calidad. Las causas se sostienen en la poca e intermitente respuesta estatal, la cual ha diferenciado su atención e invisibilizados este derecho para quienes conforman diferentes barrios.

Por otro lado, se describe a estos espacios como carentes de algún elemento distintivo. Este hecho está en relación con la discriminación a la cual se ven sometidos y marginados pues, desde el Estado, no se ha buscado resaltar a la localidad o, la diversidad cultural que los habitantes de la comunidad poseen, de tal forma, se fomente la identidad local. 
La inexistencia de elementos identitarios, pone en consideración que, la incorporación de estructuras urbanas para el disfrute y vinculación con el entorno, no significa gastos de recursos públicos, sino, justicia, es decir, "los equipamientos colectivos [...] infraestructura y servicios deben incorporar la dimensión estética como prueba de calidad humana" (Borja, 2015, p. 28). Finalmente, si se entiende que estos espacios son un bien de dominio público, es decir, a cargo del Estado (Schlack, 2007), su inacción vulnera el derecho que tienen los habitantes para acceder y usarlo sin restricciones.

Otro factor detonante producto de la temática limítrofe se evidencia en las condiciones de los tramos viales en la comuna. Por un lado, están las vías generadas desde la Zona Norte, en contraposición a la Zonal Calderón, estos últimos con un claro retroceso o detenimiento en lo que respecta a vías de calidad.

Como consecuencia colateral, la situación de los caminos y las veredas de la comuna (tramos viales de la García Moreno, correspondientes a los barrios de Llano Chico y Zonal Calderón), ponen en situación de riesgo de accidentes a los transeúntes, debido a que el deterioro de la estructura repercute en que los desplazamientos se realicen por las calles, es decir, en medio del tráfico vehicular.

Los límites territoriales son importantes, pues, minuciosamente se ve reflejado que las obras han alcanzado a ciertos barrios, los cuales pertenecen a la parroquia de Zámbiza, con cambios positivos y, daños viales o en mal estado en el caso de Llano Chico. Con lo descrito se evidencia desatención, dado que las propuestas estatales se direccionan en atender únicamente, a sus lugares de jurisdicción, no a la comuna como una totalidad.

Se resalta que la comuna es catalogada como indígena y muchos de los habitantes se autodefinen como tal. El trato desde la institucionalidad no evidencia esta cualidad, en su lugar, los sujetos participantes conciben que su connotación no ha sido valorada, ni respetada, lo que ha decantado en que sus derechos no sean escuchados.

En otras palabras, se ha dado un trato igualitario, que tiende en su lugar, invisibilizar a la diferencia. En vista de esto, otro efecto colindante como producto de la división comunal tiene que ver con la identidad de los habitantes de Cocotog, es decir, ha repercutido en que los pierdan la relación cohesiva con su territorio.

Respecto a lo planteado, Manuel Bayón Jiménez destaca las palabras de Porto-Gonçalves cuando menciona que el "territorio es espacio apropiado, espacio hecho cosa propia, en definitiva, el territorio es instituido por sujetos y grupos 
sociales que se afirman por medio de él [por tanto] hay, siempre, territorio y territorialidad, o sea, procesos sociales de territorialización" (Jiménez, 2016, p. 106).

Algo semejante resalta la psicosociología del entorno, al indicar que el espacio es importante para vivir, pues siempre estamos ubicados en uno y, es nuestra capacidad de interactuar con él, lo que favorecería la subsistencia (Valera, 1999). Con lo expuesto se quiere argumentar, que los procesos de desterritorialización tienen efectos graves en la vida de los sujetos, tal es el caso de migraciones forzadas, las cuales atraviesan por la pérdida de lugar de residencia y vínculos sociales, además "les es arrebatado su referente fundante de la definición de su identidad personal y social" (Ocampo, 2014, p. 11).

Si la indeterminación territorial ha menoscabado la identidad en los habitantes de la comuna de San José de Cocotog, se debe, principalmente, a su división en barrios, pues ha invisibilizado su pertenecía. Se exige no estar desarticulada y dividida en segmentos adscritos a alguna unidad administrativa del Estado.

Bajo los criterios esbozados, la problemática limítrofe ha vulnerado el "derecho a la identidad y preservación de las potencialidades del territorio [como] una dimensión fundamental del derecho al desarrollo" (Borja, 2015, p. 23). Este aspecto vulnerado desde la institucionalidad, ha reducido a Cocotog a una parte más de sus jurisdicciones, sin tomar en cuenta sus cualidades diversas.

Otro rasgo de la indeterminación territorial se halla en el tema de los impuestos prediales, imposición descrita como elevada, en relación con la actividad agrícola que muchos de los habitantes realizan en la comuna. Para los barrios de Cocotog, adscritos a la parroquia de Llano Chico, los gravámenes sobrepasan el coste que los habitantes podrían generar al ser catalogados como suelos urbanos, contrario con lo que sucede en Zámbiza, descritos como tierras rústicas.

Es probable que la variabilidad de costo predial este sentando las bases para un fenómeno de gentrificación en quienes habitan Llano Chico. Moradores de estas zonas que no alcancen a cubrir los pagos municipales, tenderán a vender sus propiedades. En palabras de Emilio Pradilla, la "transformación del uso del suelo de rural a urbano [...] e incremento de las rentas urbanas [producen] cambios en el régimen de propiedad de la tierra rural hacia su privatización" (Cobos, 2014, p. 42).

El hecho de ser una comunidad rural, se correlaciona a su estado de vulneraciones. Esta cualidad es catalogada como una de las causales, por las que sus habitantes ven mermada la realización de una vida digna. Las ruralidades urbanas bosquejan la marginalidad espacial de unos sectores en comparación con otros. Por ejemplo, 
se argumenta que en el área central una obra es atendida con inmediatez, caso contrario con las periferias, ocultadas y desatendidas. Se busca subrayar que "debido al crecimiento fraccionado y desigual, gran parte de la periferia no estará integrada en el desarrollo urbano" (Mérida, 2016, p. 42).

El tratamiento que la municipalidad ha hecho de la basura, ha focalizado en las comunidades el lugar en que se las arroja. La problemática no radica únicamente en que se conciba a la comuna como el espacio de acopio, pues a esto se suma el deterioro del agua que ingresa al territorio, tan necesaria para las cosechas. En la ruralidad se ha dado un empeoramiento sistemático de su hábitat, ya sea por la contaminación de sus afluentes, como por la concentración de escombros y basura producida en las urbes.

Lo expuesto permite identificar la situación de vulnerabilidad que atraviesa no solo la comuna de Cocotog, sino varias comunidades rurales. En otras palabras, se ha afectado al ambiente, entendido como el "derecho a una calidad de vida integral y como derecho a preservar el medio para las generaciones futuras, este derecho incluye [...] la protección frente a las agresiones a la calidad del entorno" (Borja, 2015, p. 30).

Producto de las entrevistas se valida el hecho de que la participación de las dirigencias locales emerge como un derecho que permite contrarrestar el estado de desatención institucional, aun cuando se verá más adelante que, la indeterminación territorial, por su efecto de división en segmentos, desarticuló la participación integral entre los cinco presidentes barriales y el principal órgano local, es decir, el cabildo.

Se ha vulnerado el derecho a la participación y a la representación, puesto que, las autoridades estatales trabajan de manera particular con los presidentes barriales, es decir, ya no pasan por el proceso estructurante de la comuna, el cual es el Cabildo. La manera en que se produce lo mencionado sienta sus bases en la división en dos parroquias, lo cual, al tomarlos como espacios independientes, genera que toda la lógica de organización local sea invisibilizada o limitada en su rol.

Es la unión de los representantes barriales, unificados como una totalidad "comunal", lo que se destaca como la mejor alternativa para su agenciamiento, de tal manera, cambiar sus condiciones de vida, a pesar de efecto provocado por la indeterminación territorial. Son los habitantes, mediante su participación, los que problematizarán la situación en su comunidad, además de incidir en la construcción de una ciudad que no los excluya. 
Para simplificar, la relación del problema limítrofe de la comuna, respecto a la afectación a sus habitantes, se lo encuentra en que estos no pueden exigir obras o cambios, puesto que no tienen una clara definición de su territorio. La actuación estatal, en este caso, ha vulnerado el derecho a la ciudad, es decir, ha afectado las condiciones de los moradores de Cocotog en la garantía de un "buen gobierno y la justicia, que sumados no es otra cosa que la garantía a la calidad de vida [...], pues todos estos valores se materializan en ese escenario dentro del cual actúan las instituciones públicas y los gobiernos" (Roa, 2012, p. 108).

\section{Discusión y conclusiones}

Resulta indudable que la indeterminación territorial ha trastocado la vida y el entorno de los habitantes de la comuna, generando discriminación y desatención estatal al momento de ver garantizados sus derechos. Esta problemática ha vulnerado la identidad, participación, acceso a espacios públicos de calidad, así también, ha ocasionado desunión y división, lo cual ha fragmentado a San José de Cocotog.

El principal efecto de la indeterminación territorial lo constituye la división de la comuna en barrios, cualidad que ha generado una atención diferente, intermitente y, en ciertos casos, inexistentes de las unidades administrativas del Estado que están a cargo de velar por la protección de sus habitantes, es decir, las administraciones zonales y juntas parroquiales. Este hecho ha provocado que quienes habitan Cocotog indiquen desprotección, mutismo y desamparo en el accionar institucional.

Es en el territorio, como espacio en que se gestan las acciones Estatales, donde se ha visto reflejada la falta de operatividad para responder a la comuna como una totalidad. En otras palabras, su responsabilidad para garantizar los derechos humanos no se materializa de forma global al interior de la comuna.

La desconfianza institucional no solo afecta la mirada que los habitantes de Cocotog hacen del Estado, es decir, como irresponsable ante la protección y la garantía de derechos, sino también, atraviesa identidades maltratadas, que se ven excluidas de la redistribución ordenada y equilibrada de los recursos de las ciudades.

La demanda de los habitantes para ver garantizados sus derechos, en una comuna consolidada y no dividida en administraciones zonales y parroquias, insta a devolver la mirada al Estado como agente capaz de reequilibrar las desigualdades y la desintegración provocada por la indeterminación territorial. La devolución de la integralidad en Cocotog decantará en la perpetuación y la supervivencia de los pueblos indígenas que lo habitan, pues su segmentación ocasiona pérdida de identidad y memoria histórica. 
Se identifica que la desvinculación de los habitantes de su territorio conforma una manera de maltrato, pues se arrebata un aspecto fundante de concepción con la que se autodefinen, tanto individual como colectivamente, esto es, la cohesión con la comuna de Cocotog atraviesa sentidos, experiencias y vivencias que, como se menciona en la Constitución del Ecuador, deben ser inembargables, inalienables e indivisibles.

La división del territorio en barrios, invisibiliza desde el Estado, la pertenencia que tienen los sujetos, es decir, como comuna indígena. Lo expuesto señala que el respecto que deben garantizar las autoridades ecuatorianas no ha velado por la integralidad de Cocotog, por tanto, ha vulnerado el derecho de los habitantes respecto a la indivisibilidad de sus tierras comunitarias.

La indeterminación territorial, en este punto, sería entendida como una forma de desterritorización, es decir, ha provocado perdida de arraigo y pertenencia. De allí que resulta imprescindible mencionar que el derecho a la propiedad comunal atraviesa su cultura, vida espiritual, integralidad y, como se mencionó, supervivencia de las poblaciones indígenas.

Se sostiene que el derecho a la ciudad pugna por la garantía en que sus habitantes vean materializada una vida digna, de manera integral e igualitaria, pero, por el contrario, la desatención Estatal a demostrado lo contrario. De esta forma, se ha segmentado a una comuna en barrios, aspecto que ha decantado en múltiples espacios territoriales en desiguales condiciones respecto a bienes y servicios de calidad.

Se resalta que la discriminación no está orientada a personas o grupos específicos, en su lugar, ocurre en espacios físicos (localizaciones) en detrimento de otros, por tanto, se trata de distinción arbitraria a nivel territorial. Este tipo de asimetrías distan de la concepción de una ciudad que genere condiciones equitativas para sus habitantes.

A pesar que normativas nacionales e internacionales abogan por que todos los sujetos puedan disfrutar sus derechos, sin ningún tipo de discriminación, el hecho de verse perjudicados por su situación de ruralidad, representa un aspecto muy distante de la inicial concepción de una ciudad pensada para todos de forma justa y equilibrada.

En su lugar, destaca la distinción que se hace entre las centralidades urbanas y las zonas rurales, como es el caso de la comuna. Las afectaciones ambientales son las vulneraciones que atraviesa la localidad, particularmente, la contaminación del agua de los caudales que ingresan al sector, además, el manejo de la basura que las autoridades focalizan en estos espacios periféricos como lugares de acopio. 
Se ha mencionado reiteradamente la relación directa que tiene el derecho a la ciudad con el espacio público, específicamente, cuando se ven materializadas las desigualdades existentes en los territorios. Bajo la problemática de la indeterminación, la atención que se da a estos sitios está atravesada por un vaivén institucional, de tal manera, las exigencias de estructuras urbanas de calidad filtran una serie de unidades administrativas que no velan por garantizar escenarios de sociabilidad colectiva e identidad de sus habitantes.

La concepción del derecho a la ciudad se convierte en un postulado que motiva a sus habitantes a la búsqueda y demanda de cambios que mejoren su situación de vida. La dirigencia de la comuna, aunadamente con sus moradores, han sabido responder mediante su participación y organización ante la desatención que detectan en sus autoridades zonales y parroquiales. La sensación de desamparo institucional ha motivado intereses locales que contrarresten el abandono provocado por la atención diferenciada a sus barrios.

Si bien la responsabilidad del Estado ecuatoriano debe favorecer e incentivar la participación local, nada demuestra que han involucrado a sus habitantes en la toma de decisión que los afecta hasta la actualidad, esto es, la división de la comuna en barrios adscritos a determinada administración zonal o junta parroquial.

Esto demuestra que desde el Estado se ha vulnerado la participación de sus habitantes en la planeación de su entorno, principalmente, en el fenómeno de la división territorial. Precisamente, es el derecho a la ciudad el mecanismo que servirá para problematizar las consecuencias del modelo de gestión que ha divido a la comuna, así también, construir aunadamente una hábitat incluyente y equilibrado, independiente de la catalogación urbana o rural.

Aun cuando se conciba que la participación y la organización colectiva representa uno de los mecanismos que el derecho a la ciudad resalta como la vía para alcanzar la vida que requieren sus habitantes, es importante destacar que la problemática limítrofe ha coartado la organización local, desarticulado la toma de decisiones de manera integral y ha deslegitimado la vía secuencial del cabildo.

Se resalta que el derecho a la ciudad genera responsabilidades, tanto para el Estado, como a sus habitantes, aunque no en las mismas proporciones. En el caso de que se trabaje de forma interrelacionada, se posibilitará la reivindicación de condiciones de segregación, carencia de espacios públicos de calidad, inseguridad, deslegitimación de la organización local y desamparo institucional en el acceso a obras y servicios. 
Finalmente, es importante mencionar que en la comuna se está produciendo un fenómeno de gentrificación, debido al efecto que la indeterminación territorial, específicamente por la distinción en el uso de suelo. Esta cualidad se ha convertido en un patrón de expulsión quienes no puedan cubrir los costes de impuestos. El incremento de las rentas urbanas que no consideran la realidad local, es decir, agrícola y ganadera, esconde el germen del cambio de moradores bajo intereses inmobiliarios y económicos.

\section{Referencias}

Alguacil, J. (2008). Espacio público y espacio político. La ciudad como el lugar para las estrategias participativas. Polis (Santiago), 51-65. https://doi.org/10.4067/ S0718-65682008000100011

Andreú, J. (2002). Las técnicas de análisis de contenido: Una revisión actualizada. Fundación Centro de Estudios Andaluces, 1-34. https://doi.org/10.2307/334486

Bayón, M. (2016). Comunidades rururbanas de Quito: entre el empresarialismo y el derecho a la ciudad. Íconos - Revista de Ciencias Sociales, 20(56), 103-122. https://doi. org/10.17141/iconos.56.2016.2068

Borja, J. (2011). Espacio público y derecho a la ciudad. Viento Sur, 116, 39-49.

Borja, J. (2015). Los derechos en la globalización y el derecho a la ciudad. Estudios Demograficos y Urbanos, 30(3), 1-44.

Castro, M. (2010). Los pueblos indígenas en latinoamérica: entre la movilización y el derecho. Revista del CESLA,197-210.

Carta de la Ciudad de México por el Derecho a la Ciudad, 76 (2010) (testimony of Ciudad de México).

Cobos, E. P. (2014). La ciudad capitalista en el patrón neoliberal de acumulación en América Latina. Cadernos Metrópole, 16(31), 37-60. https://doi. org/10.1590/2236-9996.2014-3102

Comisión de Inclusión Social Democracia Participativa y Derechos Humanos de CGLU. (2013). Carta-Agenda Mundial de Derechos Humanos en la Ciudad | CISDP. 1-15.

Constitución de la República del Ecuador, Registro Oficial 449, 20 de octubre de 2008.

Correa, L. (2012). Políticas de ciudad: planear la ciudad para reivindicar la dimensión humana. Polis Revista Latinoamericana, 11(31), 103-123. https://doi.org/10.4067/ S0718-65682012000100006 
Durán, G., Martí, M., \& Mérida, J. (2016). Crecimiento, segregación y mecanismos de desplazamiento en el periurbano de Quito. Íconos - Revista de Ciencias Sociales, 56, 123. https://doi.org/10.17141/iconos.56.2016.2150

Gonçalves, P. W. (2016). Lucha por la Tierra. POLIS, Revista Latinoamericana, 11(31), 45.

Guedes, D. D., \& Moreira, V. (2009). El método fenomenológico crítico de investigación con base en el pensamiento de Merleau-Ponty. Terapia Psicológica, 27(2), 247-257. https://doi.org/10.4067/s0718-48082009000200010

Jans, M. (2005). Ciudad y espacio público. Revista AUS, 1, 10-13. https://doi.org/10.4206/ aus.2006.n1-10

Lugo, E. (2013). Derecho de los niños y espacios jugables. La reconceptualización del juego y el niño como estrategia para la definición de un nuevo paradigma de espacios públicos abiertos a escala vecinal para la ciudad de Puebla. In UNICEF: Vol. $5^{\circ}$ Premio.

Madanipour, A.; Knierbein, S.; Degros, A. (2014). Políticas para el espcaio público en las ciudades europeas. Gestuón y Ambiente, 17, 115-137.

Mérida, J. (2016). Entre la comuna autónoma y el cliente dependiente. El ejercicio de autonomía en la comuna periurbana de Cocotog en el nuevo Estado descentralizado y plurinacional del Ecuador (Vol. 23, Issue 45). Facultad Latinoamericana de Ciencias Sociales, FLACSO Ecuador.

Misses-Liwerant, J. B. (2016). Pensar a la sociedad y al espacio público: inclusión y democracia. Revista Mexicana de Ciencias Políticas y Sociales, 61(227), 9-29. https:// doi.org/10.1016/S0185-1918(16)30020-4

Montoya, C. (2010). ¿Qué significa tener derecho a la ciudad? La ciudad como lugar y posibilidad de los derechos humanos. Territorios, 22, 125-149.

Ocampo, M. (2014). Migración forzada, desarraigo y despojo: itinerancia obligada, una ciudadanía inconclusa. Izatapalapa Revista de Ciencias Sociales y Humanidades, 35(76), 5-18. https://doi.org/10.28928/ri/762014/ptc/ocampopradom

Roa, J. C. L. (2012). El derecho al espacio público. Provincia, 27, 105-136.

Salazar, S. C., Ramos, O. L. C., \& Pérez, C. L. (2017). Espacio público, periferia urbana y derecho a la ciudad. Intervención parque Caracolí, ciudad Bolívar. Revista INVI, 32(89), 113-143. https://doi.org/10.4067/S0718-83582017000100113

Schiavo, E., Gelfuso, A., \& Vera, P. (2017). El derecho a la ciudad. Una mirada desde América Latina. Cuadernos Metrópole, 299-312. https://doi.org/10.1590/2236-9996.2017-3812 
Schlack, E. (2007). Espacio público. Arquitectura, derecho y urbanismo ARQ, 65, 25-27. https://doi.org/10.4067/S0717-69962007000100006

Valera, S. (1999). Espacio privado, espacio público: Dialécticas urbanas y construcción de significados. Tres Al Cuarto, 6, 22-24. 